\title{
After the Aftershocks
}

\author{
Tom Daniell
}

In November 2010, I was asked by the chief editor of Volume (a Dutch-American architecture journal for which I'm an editorial advisor) to contribute a short text based on my spontaneous, unconsidered response to a swatch of pale blue he had sent to me by e-mail. Many other people received the same request: artists, architects, graphic designers, writers, philosophers, and so on. To me it simply suggested the sea - not a particularly original reaction, to be sure - and I sent him this paragraph:

Spending most of my life on island nations (New Zealand, Japan), I'm always close to a coast. On the best days, a tessellating, coruscating field of blue stretches from your feet to the horizon, then curves back as a smooth canopy gradually deepening in hue. The ground shakes violently from time to time, as if suspended in a precarious equilibrium, and then you watch for the horizon itself to rise - the ironically named $\mathrm{Pa}-$ cific Ocean always threatening to return everything to blue.

The collected responses were published the following month, in Volume issue 26. On March 11, 2011, the Pacific Ocean did rise and inundate part of the northeast coast of Japan. There is no cause and effect here, obviously. It was (is) always just a matter of time, but nonetheless the timing gave me a chill. I was in China that day, reaching the end of a month-long design studio at a local university. As I walked into the room for the final review, the students immediately told me a large earthquake had just hit Japan, measuring 8 on the Richter scale. I didn't yet know the epicentre, but I knew the potentially horrific implications of that number if it was anywhere near a city (in fact the magnitude was later determined to have been 9 - a barely conceivable 10 times stronger - and considered the most powerful earthquake ever to have struck Japan). At that point, there was nothing to be done. We began the review. Within 24 hours I was back home in Kyoto, having flown on a half-empty plane, waited in an almost non-existent queue for the "Foreigners" desk at immigration, and encountered a series of sober but admirably good-humoured airport staff, train passengers, and taxi drivers.

Only a few weeks earlier I had spent several days making and fielding phone calls and e-mails reacting to the Christchurch quake. I now did the same regarding Japan. To avoid clogging the overburdened phone lines, Facebook and Twitter became ideal ways to check on the status of acquaintances closer to the disaster area, their updates letting us know about the situation in real time, as well the simple fact that they were alive. As the death toll headed into the tens of thousands - entire villages erased from the earth - it became terrifyingly clear that the real problem was nuclear. A cracked reactor at Fukushima was releasing unknown quantities of radiation into the air and sea. Even amid the panic and misinformation of those early days, it was obviously going to be a profound catastrophe for Japanese society, and a long-term problem for the entire world.

Since then, in almost every lecture, every email, every conversation, I am asked to comment on the situation in Japan, my home for the last 18 years. Of course, it's impossible for me not to say something, but in a sense it's also impossible for me to say anything at all. By that I mean: words are inadequate to capture this level of 


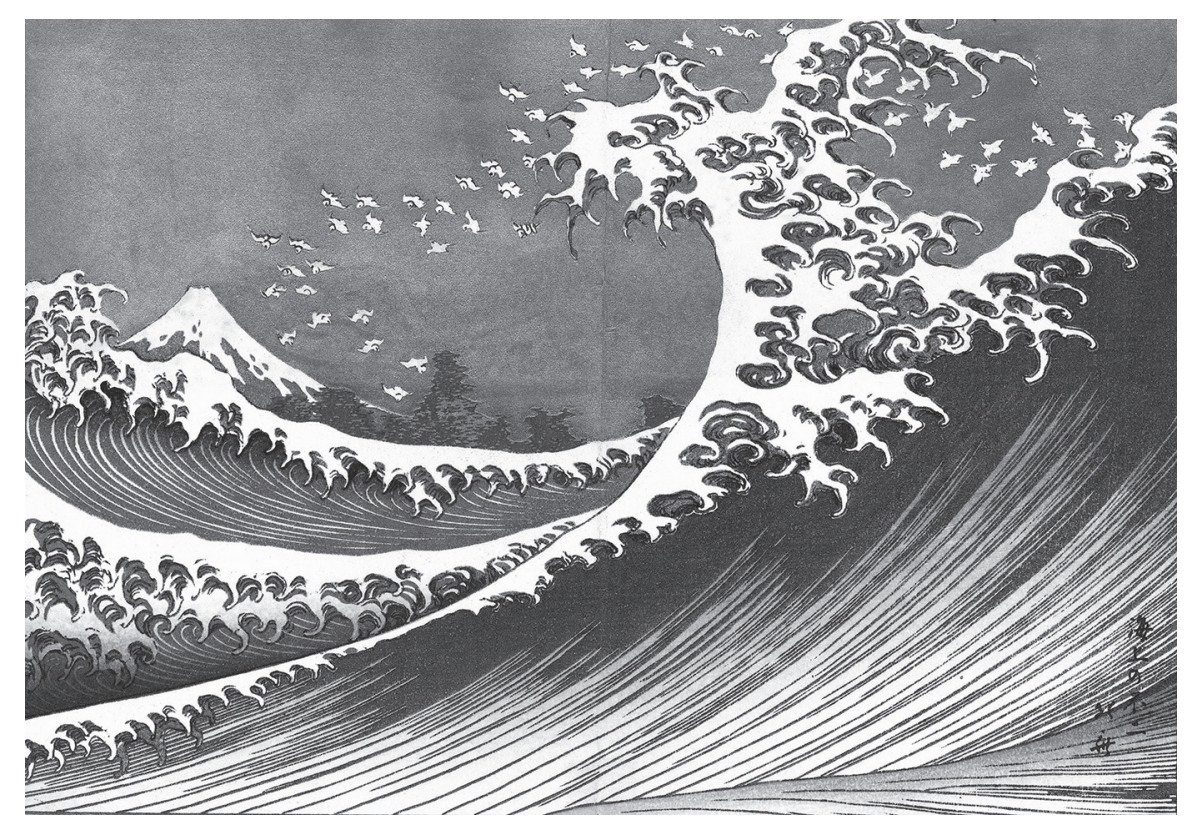

devastation and tragedy. Every description, no matter how it's phrased, seems too weak or else trying too hard, like disaster-movie advertising copy. Our vocabulary for such events is irredeemably clichéd. I'm reminded of the author Martin Amis, who has spent his career in what he calls "the war against cliché" but in his memoir Experience makes the very insightful remark that - I'm paraphrasing from memory - you know you are experiencing a transformative moment when tired clichés suddenly regain the power that they must have possessed when first formulated.

Hundreds of kilometres away in Kyoto, we experienced very little hardship in the weeks following the quake. There were occasional shortages in the supermarkets and temporary quotas on bottled water as supplies were redirected to the survivors. Via television and the Internet, we tracked the aftershocks and followed progress at the Fukushima reactor as a small group of workers diligently tried to staunch the leaking radioactivity, exposing themselves to levels that effectively meant committing slow suicide for the sake of the nation. In conversation with an American friend, I described them as heroes and their behaviour as quintessentially Japanese. He agreed that they were heroes, but insisted that you would find a similar group of volunteers in the United States if something similar happened there. True enough, but I suspect that American (Western) heroism emerges partly out of a desire for personal, and possibly posthumous, fame - and is no less admirable for that - whereas Japanese heroism emerges from a sense of anonymous humility and solidarity.

Indeed, one of the recurrent clichés about the aftermath is the orderliness, cooperativeness, and stoicism of the people. There was no rioting or looting, almost no opportunistic crime of any kind. As with the Kobe earthquake in 1995, there is a surreal quality to seeing a nation in which everything seems so precisely controlled overwhelmed by brute natural forces. But Japan has always lived with imminent disaster: earthquakes, fires, floods, typhoons, tsunamis. The natural world is regarded with awe and fear. Japanese traditional culture's reputed "harmony with nature" - one of the most persistent clichés - is in many respects a sophisticated attempt to filter and tame the unpredictability of nature. The aestheticisation of the natural environment (bonsai trees, landscaped gardens, the
Katsushika Hokusai (1760-1849). A version of the Kanagawa wave from the 36 views of Mt Fuji [Wikimedia Commons] 
rituals associated with seasonal change) is intended as symbolic control of essentially uncontrollable wildness. Long-term survival depends on social harmony, discipline, hierarchy, loyalty, and consensus. And, all too often, on the willingness of individuals to sacrifice themselves for the good of the collective. For better or worse, this set of attitudes is, I think, the source of Japan's incredible resilience and inventiveness, its capacity to constantly rebuild itself, even redesign itself.

The aftershocks continue sporadically even as I write. In a sense, this has all been one long quake varying in intensity over many months. Sooner or later Japan is guaranteed to experience something similar all over again - and again, and again. Elsewhere and differently, perhaps, but inevitably. The northeast coastline of Japan is dotted with "tsunami stones": megaliths up to three metres tall and six centuries old, engraved with warnings to run inland the moment an earthquake hits, or not to build any closer to the sea than where they are embedded. Over the centuries, the latter warnings had been increasingly ignored, sea walls and modern communication technologies supposedly making them redundant. With the 20/20 hindsight of an armchair expert it's easy enough to criticise the complacency and willful ignorance, the unpreparedness of the populace, the shocking vulnerability of the nuclear facility, and so forth. At the same time, we shouldn't lose sight of the astounding lack of earthquake damage to buildings in Tokyo and elsewhere, the minimal loss of life due to the earthquake alone.

A year on, the degree to which the afflicted regions have recuperated is astonishing and moving, though not altogether surprising - recall that the Hiroshima branch of the Bank of Japan was open for business within two of days of the atomic bombing in 1945 . So, what to do now, once the mess has been cleaned up, the dead buried, and the survivors housed? The crucial issue, or at least the one most under human control, is nuclear power. Following the meltdown, many of Japan's nuclear plants have been shut down pending safety tests, while Germany, for example, has vowed to permanently close down all its plants within 10 years. Statistics may attribute more deaths to coal mining than nuclear energy, but coal-mining deaths are almost entirely confined to the miners themselves, with no impact on the wider public, no long-term poisoning of the environment, no genetic damage to children in the womb. To be sure, we are bombarded with radiation constantly - a transatlantic flight supposedly exposes you to more radiation than a visit to Tohoku today, and Rome on any given day is still more radioactive than Tokyo after the quake. Debates among the experts about the relative dangers of nuclear power leave laypersons with little option other than to subscribe to the view that best fits their own prejudices. But no matter how sophisticated our defensive measures become, there is always going to be a tsunami bigger than any sea wall, an earthquake stronger than any building foundation. In Japan, and elsewhere, all that can be done is to create architecture and infrastructure that demonstrates intelligence in its construction, respect for its users, and humility toward the blind forces of the natural world. 